\title{
An integrated framework for cost- benefit analysis in road safety projects using AHP method
}

\author{
Mahsa Mohamadian $^{\mathrm{a}}$, Siamak Noori ${ }^{\mathrm{a}^{*}}$ and Seyed Mohamad Seyed Hosseini ${ }^{\mathrm{a}}$
}

${ }^{a}$ Department of Industrial Engineering, Iran University of Science \& Technology, Tehran, Iran

\begin{tabular}{|c|c|}
\hline ART I CLEINFO & ABSTRACT \\
\hline $\begin{array}{l}\text { Article history: } \\
\text { Received February 20, } 2011 \\
\text { Received in Revised form } \\
\text { April, 30, } 2011 \\
\text { Accepted 15 May } 2011 \\
\text { Available online } \\
17 \text { May 2011 } \\
\text { Keywords: } \\
\text { Cost benefit analysis (CBA) } \\
\text { Analytical hierarchy process } \\
\text { (AHP) } \\
\text { Road safety }\end{array}$ & $\begin{array}{l}\text { Cost benefit analysis (CBA) is a useful tool for investment decision-making from economic } \\
\text { point of view. When the decision involves conflicting goals, the multi-attribute analysis } \\
\text { approach is more capable; because there are some social and environmental criteria that cannot } \\
\text { be valued or monetized by cost benefit analysis. The complex nature of decision-making in } \\
\text { road safety normally makes it difficult to reach a single alternative solution that can satisfy all } \\
\text { decision-making problems. Generally, the application of multi-attribute analysis in road sector } \\
\text { is promising; however, the applications are in preliminary stage. Some multi-attribute analysis } \\
\text { techniques, such as analytic hierarchy process (AHP) have been widely used in practice. This } \\
\text { paper presents an integrated framework with CBA and AHP methods to select proper } \\
\text { alternative in road safety projects. The proposed model of this paper is implemented for a case } \\
\text { study of improving a road to reduce the accidents in Iran. The framework is used as an aid to } \\
\text { cost benefit tool in road safety projects. }\end{array}$ \\
\hline
\end{tabular}

\section{Introduction}

Cost-benefit analysis (CBA) has been used as a proper tool for assessing proposed public projects since the middle of last century. In fact, CBA was originally created to apply for projects taken in charge by the public sector (Campbell \& Brown, 2005). Road infrastructures are one of the projects undertaken by this sector. CBA is used when deciding about investments in road projects (Ivehammar, 2008). Additionally, CBA has been used for many years to make priorities for road safety projects. Its application goes approximately more than 2 decades back, but has remained arguable yet (Hauer, 1994). Joksch (1975) in an evaluation of the suitability of CBA to road safety measures, concluded that there were so many problems in approximating both costs and benefits that one should not trust in CBA to decide whether road safety measures must be applied or not. However, his criticism did not question the basic rules of CBA; but another critic like Hauer (1994), refused the basic rules of CBA in the field of road safety. He believes that putting a monetary value on human life is ethically improper.

\footnotetext{
* Corresponding author. Tel. $+98(21) 77240000$

E-mail addresses: noori@iust.ac.ir (S. Noori) 
Elvik (2001) identified some types of criticism for CBA: (1) basic rules of CBA are not applicable to road safety; (2) some types of road safety costs and benefits cannot be calculated by CBA; (3) setting road safety policy goals are not manageable by CBA. Additionally, Elvik (2003) criticized CBA, because only a few road safety measures are cost-effective and their benefits are more than their costs. He presented cost-effective road safety policies could stop up to $60 \%$ of the current number of road accident, for a period of 10 years. However, CBA would only stop up to $15 \%$ of the current number of road accident during the next 10 years.

Wijnen et al. (2009) declared in many of road safety projects, putting human lives in monetary value, is an important issue. They discussed the value of a statistical life (VoSL) and willingness to pay (WTP) as concepts that are often applied to calculate safety effects in monetary form of road safety measure. They compared VoSL method with other methods specially the human capital method and quality adjusted life year's method in order to monetize road safety effects. They discussed detecting the benefits of road safety project are often arguable. Bax et al. (2009) found that the ranking of road safety projects based on the results of economic evaluation, specifically CBA, has some limitations. They presented some reasons for this fact and designed a framework by knowledge utilization theory for detecting the limitations. They investigated these limitations by interviewing 83 road safety DMs in various European countries. As a result, various technical limitations such as lack of knowledge of the benefits of road safety measures were found.

Elvik (2009) discussed the relationship between efficiency and equity as two main tools of road safety policy. In order to make road safety measures efficient, prioritization must be exactly compatible to CBA tool. However, setting priorities for safety measures completely based on CBA won't result in assumed equity and fairness. It is concluded that there is a struggle between efficiency and equity providing road safety. Providing much equity would be far than efficiency, as the only aim for setting policy priorities. Elvik (2010) discussed about motivations for making priorities in road safety policy, more efficient by the use of cost-effective road safety measures. He argued that much of benefits of road safety measures could not be monetized in market and would never increase the income or profit. Therefore, the influence of real road safety policy must be empowered by some other strategies.

Elvik (2010) declared that some road safety problems have lasted for a long time. He argued that the characteristics that can make a problem difficult to solve are to some extent associated with human behavior and believes. Hauer (2011) declared that these two parameters associated with human have been the most controversial and dissolvable issues of CBA in road safety projects. He argued that the CBA tool is not efficient because: (1) estimates of the value of statistical life and injury depends on the place and it is in contrary with the value of time estimates; (2) CBA needs to calculate present values by discounting the value of future lives and time. As a result, time savings are valued much more than real when it is compared to life. As discussed earlier, there have been enormous researches about road safety projects and the problems of benefits and costs measurement. The results of all researches show that assessing road safety projects by CBA would cause only few roads to improve, because considering the rule that monetary benefits must exceed costs will not result in a large improvement in safety. On the other hand, it is not fair to reject improving safety in roads only because monetary benefits are smaller than monetary costs. Now it is time to develop CBA tool with some techniques that are able to consider quantitative factors beyond the qualitative. In order to solve the mentioned problems and issues, some researchers have developed new methods to use alternative methods instead of CBA or as a complementary aid to help DMs estimate exact benefits and costs of road projects. Decorla-Souza et al. (1997) explained the new method of total cost analysis (TCA) in order to compare transportation project alternatives. The method calculates full costs of each alternative like travel time costs, monetized environmental and social costs; so that some costs assumed as the benefits in the form of saving mode in BCA would bring to the costs side in TCA. The most important advantage of TCA over current BCA is that the meaning of total cost can be 
more understood by public rather than BCA terms like internal rate of return. Another advantage is that DMs are free to consider whatever benefit they accept as the result of the project and there is no obligation to calculate all benefits. Womer et al. (2006) developed a method, which conducts CBA using data envelopment analysis (DEA). The new method covers most deficiencies of CBA and gives DMs a tool to assess different projects with conflicting views. Salling et al. (2009) presented a model in order to evaluate transport infrastructure projects called CBA-DK. The model integrates current CBA as a start point, with quantitative risk analysis by Monte Carlo simulation. The main issues of the model are current CBA concerns such as travel time savings and human life value. The proposed evaluation model uses both deterministic and stochastic based data. This model is used as a decision support in providing road policy making.

In this paper, a new framework is presented that uses multiple criteria decision making (MCDM) as an aid to help economic evaluation more efficient and helpful. MCDM helps find the best opinion from all of the possible alternatives in the presence of multiple, usually conflicting, decision criteria (Torfi et al., 2010). Analytical hierarchy procedure (AHP) is one of the MCDM's methods developed by Saaty and is perhaps the most famous and widely acceptable method. The main advantage of the AHP is that it is user-friendly. Some other advantages are unity in process, systematic analysis of complex problems, hierarchy structuring of decision process, consistency and trade-off between different criteria (Dyer \& Wendel, 1985). Its simplicity of use is due to an exclusive integration of design attributes. It considers both qualitative and quantitative attributes together (Dolan, 2008). AHP is the most successful application in group decision making (Harker, 1987; Zahedi, 1987). AHP has been widely used in different projects such as prioritization of water resources projects, environment studies, road and highway constructions, etc. However, there has been no research or method to use AHP in CBA of road safety project.

This paper is organized as follows. We first present the proposed methodology of our research in section 2. Section 3 explains the details of our implementation and finally section 4 summarizes the contribution of the paper.

\section{The proposed framework}

The proposed model of this paper uses an integrated method to combine CBA with AHP in order to provide a framework for economic evaluation of road safety projects. Organizing the proposed framework, we need to gather required data and information to form criteria and attributes that affect economic evaluation of road safety projects. Literature review of the previous studies gave us some traits considered as criteria. We also gathered DM's opinions by interviewing them and 5 criteria and 23 sub-criteria were recognized. Finding the importance of each criteria and sub - criteria in hierarchy, pairwise comparisons would elicit for each level of hierarchy to obtain the weights for each level based on one element in the next highest level. We could find the local weights of all criteria and sub-criteria. Eventually, the AHP algorithm was applied to the data and the results were analyzed. Finally, we implemented the proposed model of this paper for a case study in Azerbayjan, Iran. The proposed case study aimed to improve the traffic jam in Miyaneh - Tikmehdash one lane road to two lane one.

First, to gather the necessary information, we chose seven experts in the field of road safety economic and project managing. All the experts were familiar with the most important issues of CBA in road safety projects. Interviewing these experts helped us find criteria and sub-criteria affecting the economic evaluation of road safety projects; Table 1 summarizes them. As we see, the determined criteria are completely independent from each other so that applying AHP method would completely lead to correct results. Note that in case there are some dependency among data we need to use ANP. 


\section{Table 1}

Criteria and sub - criteria affect economic evaluation of road safety projects

\begin{tabular}{|c|c|c|c|}
\hline No. & Criteria & Description & Sub-criteria \\
\hline 1 & Economic attributes (A) & Quantitative & $\begin{array}{ll}\text { 1. } & \text { Construction cost }\left(A_{1}\right) \\
\text { 2. } & \text { Design, control \&management costs }\left(A_{2}\right) \\
\text { 3. } & \text { Site acquisition }\left(A_{3}\right) \\
\text { 4. Life-cycle maintenance costs }\left(A_{4}\right) \\
\text { 5. Opportunity cost of land loss }\left(A_{5}\right) \\
\text { 6. }\end{array}$ \\
\hline 2 & Transportation attributes (B) & $\begin{array}{l}\text { Quantitative } \\
\& \\
\text { Qualitative }\end{array}$ & $\begin{array}{l}\text { 1. Travel time saving }\left(\mathrm{B}_{1}\right) \\
\text { 2. Vehicle Operating cost saving }\left(\mathrm{B}_{2}\right) \\
\text { 3. Accident costs saving }\left(\mathrm{B}_{3}\right) \\
\text { 4. Improving the proportion of road length to area } \\
\left(\mathrm{B}_{4}\right) \\
\text { 5. Facilitating the access between origin and } \\
\text { destination }\left(\mathrm{B}_{5}\right) \\
\text { 6. Facilitating the access between population centers } \\
\text { along the road }\left(\mathrm{B}_{6}\right)\end{array}$ \\
\hline 3 & Social attributes (C) & Qualitative & $\begin{array}{l}\text { 1. Tourism development in project area }\left(\mathrm{C}_{1}\right) \\
\text { 2. Social \& cultural development in project area }\left(\mathrm{C}_{2}\right) \\
\text { 3. Job Creation in project area }\left(\mathrm{C}_{3}\right) \\
\text { 4. Deprivation poverty reduce in project area }\left(\mathrm{C}_{4}\right) \\
\text { 5. Improvement the income per capita and GDP in } \\
\text { project area }\left(\mathrm{C}_{5}\right)\end{array}$ \\
\hline 4 & Environmental attributes (D) & Qualitative & $\begin{array}{l}\text { 1. Environmental pollution costs during the } \\
\text { construction }\left(\mathrm{D}_{1}\right) \\
\text { 2. Environmental pollution costs during the } \\
\text { operating years }\left(\mathrm{D}_{2}\right) \\
\text { 3. Mitigating measures costs to reduce adverse } \\
\text { environmental impacts }\left(\mathrm{D}_{3}\right) \\
\text { 4. Non-monetizing adverse environmental impacts } \\
\left(\mathrm{D}_{4}\right)\end{array}$ \\
\hline 5 & Strategic attributes (E) & Qualitative & $\begin{array}{l}\text { 1. Passive defense \& strategic development }\left(E_{1}\right) \\
\text { 2. International transportation development }\left(E_{2}\right)\end{array}$ \\
\hline
\end{tabular}

In the second step, in order to determine local weight of each criteria and sub - criteria, we have used DM's feedback on each factor so that pairwise comparison matrices of relevant contribution have been constructed and experts could compare the attributes. The numerical scale used for assessing values to these comparative rating is shown in Table 2 (Henderson \& Dutta, 1992).

\section{Table 2}

Scale of relative importance used in pairwise comparisons

\begin{tabular}{ll}
\hline Intensity of relative importance & Definition \\
\hline 1 & Equal importance \\
3 & Moderate importance of one over another \\
5 & Essential or strong importance \\
7 & Demonstrated importance \\
$2,4,6,8$ & Extreme importance \\
\hline
\end{tabular}

Since there is more than one DM, we would have 7 pairwise matrices for criteria and 35 pairwise matrices for sub - criteria. In order to find group comparison matrices, we have used geometric mean. Finally, the group decision matrices allow us to find the local weights of each criteria and subcriteria. Table 3 summarizes the local weights of criteria and sub-criteria. 
Table 3

The local weights of criteria and sub-criteria

\begin{tabular}{llll}
\hline Criteria & Local weight & Sub - criteria & Local weight \\
\hline A & 0.24 & $\mathrm{~A}_{1}$ & 0.42 \\
& & $\mathrm{~A}_{2}$ & 0.05 \\
& & $\mathrm{~A}_{3}$ & 0.15 \\
& & $\mathrm{~A}_{4}$ & 0.16 \\
$\mathrm{~B}$ & & $\mathrm{~A}_{5}$ & 0.17 \\
& \multirow{4}{*}{0.19} & $\mathrm{~A}_{6}$ & 0.05 \\
& & $\mathrm{~B}_{1}$ & 0.12 \\
& & $\mathrm{~B}_{2}$ & 0.11 \\
& & $\mathrm{~B}_{3}$ & 0.45 \\
$\mathrm{C}$ & & $\mathrm{B}_{4}$ & 0.07 \\
& & $\mathrm{~B}_{5}$ & 0.08 \\
& \multirow{3}{*}{0.26} & $\mathrm{~B}_{6}$ & 0.18 \\
& & $\mathrm{C}_{1}$ & 0.08 \\
& & $\mathrm{C}_{2}$ & 0.14 \\
$\mathrm{D}$ & $\mathrm{C}_{3}$ & 0.12 \\
& & $\mathrm{C}_{4}$ & 0.43 \\
& & $\mathrm{C}_{5}$ & 0.23 \\
$\mathrm{E}$ & 0.22 & $\mathrm{D}_{1}$ & 0.12 \\
& & $\mathrm{D}_{2}$ & 0.20 \\
& & $\mathrm{D}_{3}$ & 0.12 \\
& & $\mathrm{D}_{4}$ & 0.57 \\
\hline
\end{tabular}

In step 3, we must determine the inconsistency within the matrices. The consistency index (C.I.) is used to estimate the consistency in experts' judgments. The index of C.I. has been suggested by Saaty as a measure of inconsistency of the judgments. Typically, if C.I. is equal or less than 0.1, the judgment would be taken as acceptable, otherwise the DM is urged to reconsider his/her judgment (Saaty \& Vargas, 1984). Table 4 presents the inconsistency of judgments.

Table 4

Inconsistency ratio of experts' judgment

\begin{tabular}{|c|c|c|c|c|c|c|c|}
\hline $\begin{array}{l}\text { Pairwise } \\
\text { comparison matrix }\end{array}$ & $\begin{array}{l}\text { Expert } \\
\text { No. } 1\end{array}$ & $\begin{array}{l}\text { Expert } \\
\text { No. } 2\end{array}$ & $\begin{array}{l}\text { Expert } \\
\text { No. } 3\end{array}$ & $\begin{array}{l}\text { Expert } \\
\text { No. } 4\end{array}$ & $\begin{array}{l}\text { Expert } \\
\text { No. } 5\end{array}$ & $\begin{array}{l}\text { Expert } \\
\text { No. } 6\end{array}$ & $\begin{array}{l}\text { Expert } \\
\text { No. } 7\end{array}$ \\
\hline Criteria & 0.07 & 0.05 & 0.01 & 0.05 & 0.01 & 0.08 & 0.02 \\
\hline Sub - criteria (A) & 0.06 & 0.08 & 0.06 & 0.09 & 0.09 & 0.06 & 0.09 \\
\hline Sub - criteria (B) & 0.08 & 0.04 & 0.07 & 0.06 & 0.08 & 0.08 & 0.03 \\
\hline Sub - criteria (C) & 0.06 & 0.01 & 0.06 & 0.03 & 0.03 & 0.06 & 0.06 \\
\hline Sub - criteria (D) & 0.02 & 0.09 & 0.06 & 0.06 & 0.01 & 0.01 & 0.09 \\
\hline Sub - criteria (E) & - & - & - & - & - & - & - \\
\hline
\end{tabular}

As we see in Table 4, all judgments have acceptable inconsistency ratio.

\section{The implementation of AHP}

Analyzing gathered data, the proposed model of this paper is applied for a case study considered as improvement of Miyaneh - Tikmehdash one lane road to a divided two-lane one. Feasibility study of this project gave us 7 different alternatives. In order to select the ideal one, different assessments such as technical, financial and economic evaluation are performed. After technical and financial assessments, only 3 alternatives are accessed to economic evaluation step. Selecting the best 
alternative needs the implementation of CBA tool; but in this paper, we use proposed model to select the best alternative among the three possible choices.

\subsection{Solution methodology}

The analysis begins with pairwise comparisons and development of normalized matrix. Consistency indices must then be calculated. Table 5 shows the results of comparison matrices and the inconsistency of judgment in each matrix. It must be mentioned that $\mathrm{X}, \mathrm{Y}$ and $\mathrm{Z}$ stand for alternative No. 1, 2 and 3, respectively.

\section{Table 5}

Results of alternative comparisons and inconsistency of judgments

\begin{tabular}{llllll}
\hline Criteria & $\begin{array}{l}\text { Sub } \\
\text { criteria }\end{array}$ & $\begin{array}{l}\text { Local weight of } \\
\mathrm{X}\end{array}$ & $\begin{array}{l}\text { Local weight of } \\
\mathrm{Y}\end{array}$ & $\begin{array}{l}\text { Local weight of } \\
\text { Z }\end{array}$ & $\begin{array}{l}\text { Inconsistency } \\
\text { ratio of judgment }\end{array}$ \\
\hline $\mathrm{A}$ & $\mathrm{A}_{1}$ & 0.449 & 0.281 & 0.269 & 0 \\
& $\mathrm{~A}_{2}$ & 0.449 & 0.281 & 0.269 & 0 \\
& $\mathrm{~A}_{3}$ & 0.557 & 0.234 & 0.209 & 0 \\
& $\mathrm{~A}_{4}$ & 0.459 & 0.278 & 0.363 & 0 \\
& $\mathrm{~A}_{5}$ & 0.557 & 0.234 & 0.209 & 0 \\
& $\mathrm{~A}_{6}$ & 0.465 & 0.275 & 0.260 & 0 \\
$\mathrm{~B}$ & $\mathrm{~B}_{1}$ & 0.072 & 0.649 & 0.279 & 0.06 \\
& $\mathrm{~B}_{2}$ & 0.763 & 0.176 & 0.061 & 0.09 \\
& $\mathrm{~B}_{3}$ & 0.814 & 0.114 & 0.072 & 0.05 \\
& $\mathrm{~B}_{4}$ & 0.089 & 0.352 & 0.559 & 0.05 \\
& $\mathrm{~B}_{5}$ & 0.333 & 0.333 & 0.333 & 0 \\
& $\mathrm{~B}_{6}$ & 0.785 & 0.149 & 0.066 & 0.07 \\
$\mathrm{C}$ & $\mathrm{C}_{1}$ & 0.744 & 0.150 & 0.106 & 0.10 \\
& $\mathrm{C}_{2}$ & 0.072 & 0.649 & 0.279 & 0.06 \\
& $\mathrm{C}_{3}$ & 0.163 & 0.297 & 0.540 & 0.01 \\
& $\mathrm{C}_{4}$ & 0.072 & 0.649 & 0.279 & 0.06 \\
& $\mathrm{C}_{5}$ & 0.169 & 0.443 & 0.387 & 0.02 \\
$\mathrm{D}$ & $\mathrm{D}_{1}$ & 0.750 & 0.171 & 0.078 & 0.09 \\
& $\mathrm{D}_{2}$ & 0.798 & 0.138 & 0.064 & 0.09 \\
& $\mathrm{D}_{3}$ & 0.747 & 0.134 & 0.119 & 0.01 \\
& $\mathrm{D}_{4}$ & 0.785 & 0.149 & 0.066 & 0.07 \\
\hline $\mathrm{E}$ & $\mathrm{E}_{1}$ & 0.143 & 0.429 & 0.429 & 0 \\
& $\mathrm{E}_{2}$ & 0.333 & 0.333 & 0.333 & 0 \\
\hline
\end{tabular}

After finding the local weights, in this step we calculated the overall weight for each alternative in order to rank them. Overall weight of each alternative is a modulation of all local weight. Fig. 1 shows the final result of ranking alternatives by the proposed model of this paper.

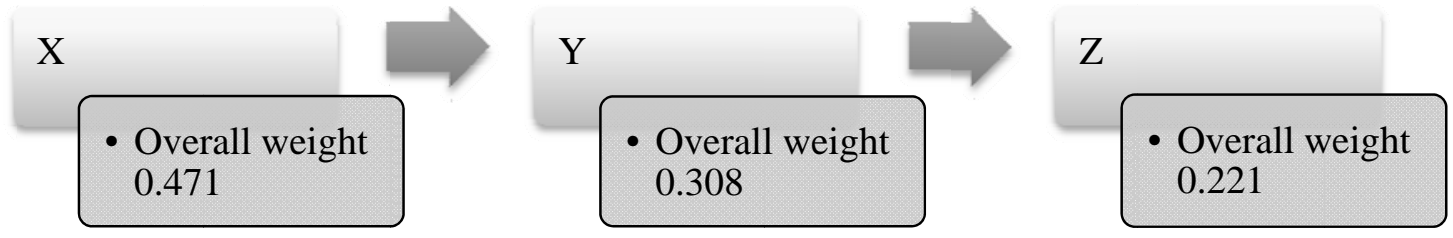

Fig.1. The priority of the three alternatives 


\subsection{Validation}

After ranking the alternatives, the results of the implementation of our proposed model in real-world case study of this paper must be validated. There are some techniques to help DMs make decision if a project is economically justified or not such as net present value (NPV), benefit to cost ratio (BCR) and economic rate of return (ERR). In fact, the Miyane - Tikmehdash project has been analyzed by these three techniques. In order to find the mentioned indices the different costs of alternatives must be calculated as shown in Table 6.

\section{Table 6}

Operational costs of alternatives - Billion Rials

\begin{tabular}{lllllll}
\hline Alternative & Construction & $\begin{array}{l}\text { Design, } \\
\text { control } \\
\text { \&management }\end{array}$ & $\begin{array}{l}\text { Site } \\
\text { acquisition }\end{array}$ & $\begin{array}{l}\text { Life-cycle } \\
\text { maintenance }\end{array}$ & $\begin{array}{l}\text { Opportunity } \\
\text { cost of land } \\
\text { loss }\end{array}$ & $\begin{array}{l}\text { Unexpected } \\
\text { costs }\end{array}$ \\
\hline $\mathrm{X}$ & 824.20 & 123.63 & 127.10 & 365.09 & 276.94 & 107.49 \\
$\mathrm{Y}$ & 1316.08 & 197.41 & 302.40 & 602.38 & 658.91 & 181.59 \\
$\mathrm{Z}$ & 1374.25 & 206.14 & 338.40 & 635.44 & 737.36 & 191.88 \\
\hline
\end{tabular}

After the costs were determined, the benefits of each alternative must be calculated and compared with the base case. The base case in this project is to continue without doing any improvement in the road. Table 7 shows the benefits considered in CBA of the project.

Table 7

Benefits of the alternative compared with base case in first year of operating - Billion Rials

\begin{tabular}{lllll}
\hline Alternative & $\begin{array}{l}\text { Travel time } \\
\text { saving }\end{array}$ & $\begin{array}{l}\text { Vehicle gas cost } \\
\text { saving }\end{array}$ & $\begin{array}{l}\text { Vehicle Operating cost } \\
\text { saving excluding gas }\end{array}$ & Accident costs saving \\
\hline $\mathrm{X}$ & 21.36 & -13.55 & 0.10 & 202.37 \\
$\mathrm{Y}$ & 28.20 & -9.19 & -12.33 & 202.37 \\
$\mathrm{Z}$ & 25.92 & -42.50 & -16.89 & 202.37 \\
\hline
\end{tabular}

In this step, we calculate the net present value of different alternatives $\mathrm{X}, \mathrm{Y}$ and $\mathrm{Z}$ with $12 \%$ discount rate. The rate is used based on the rules and regulations obtained from President Deputy Strategic Planning and Control. Table 8 summarizes the results of our finding.

Table 8

Results of CBA in the improvement of Miyaneh - Tikmehdash road

\begin{tabular}{llll}
\hline Alternative & NPV (Billion Rials) & BCR & ERR \\
\hline $\mathrm{X}$ & 330.61 & 1.36 & $16.50 \%$ \\
$\mathrm{Y}$ & -289.96 & 0.82 & $9.21 \%$ \\
$\mathrm{Z}$ & -609.61 & 0.64 & $6.05 \%$ \\
\hline
\end{tabular}

The results of Table 8 shows that $\mathrm{X}$ is more preferred than $\mathrm{Y}$ and $\mathrm{Y}$ is more preferred than $\mathrm{Z}$ and it is similar to the result of the proposed method of this paper. In addition, based on CBA we can find that only X can be performed because the NPV index for other alternatives are less than zero. Another result is that, as the proposed method cannot show the rate of NPV for the alternatives so it cannot be used alone in the economic evaluation of road safety projects; otherwise, it must be used as a complementary method to CBA.

\section{Conclusion}

In this paper, we have presented a new framework based on cost - benefit analysis and analytic hierarchy process for ranking road safety alternatives. The proposed model determined various criteria by literature review and decision makers' opinion. The proposed model was implemented for a real-world case study of improving Miyaneh - Tikmehdash one lane road to a divided two-lane road in order to reduce the accidents. The results of this model were validated by some other 
techniques such as net present value that is being used to prioritize the road projects. Since the results of both models were similar, our proposed model could be used for many other real-world applications. It must be mentioned that the proposed model must be used as a complementary method to help CBA justifying the road safety projects; since the model only ranks the alternatives and it cannot show whether the alternative is economically justified or not.

\section{References}

Bax, C., Elvik, R, \& Veisten, K. (2009). Knowledge utilization in road safety policy: Barriers to the use of knowledge from economic analysis. Knowledge, Technology \& Policy, 22(4), 275-285.

Campbell, H. \& Brown, R. (2005). A multiple account framework for cost -benefit analysis. Evaluation and Program Planning, 28(1), 23-32.

Decorla-Souza, P., Everett, J., Gardner, B. \& Culp, M. (1997). Total cost analysis: An alternative to benefit-cost analysis in evaluating transportation alternatives. Transportation, 24(2), 107-123.

Dyer, J.S. \& Wendel, R.E. (1985). A Critique of Analytic Hierarchy Process. Working Paper 84/854-24. Department of Management, The University of Texas at Austin.

Dolan J.G. (2008). Shared decision-making - transferring research into practice: The Analytic Hierarchy Process (AHP). Patient Education and Counseling, 73(3), 418-425.

Elvik, R. (2001). Cost-benefit analysis of road safety measures: Applicability and controversies. Accident Analysis and Prevention, 33(1), 9-17.

Elvik, R. (2003). How would setting policy priorities according to cost-benefit analyses affect the provision of road safety?. Accident Analysis and Prevention, 35(4), 557-570.

Elvik, R. (2009). The trade - off between efficiency and equity in road safety policy. Safety Science, 47(6), 817-825.

Elvik, R. (2010). Strengthening incentives for efficient road safety policy priorities: The roles of cost - benefit analysis and road pricing. Safety Science, 48(9), 1189-1196.

Elvik, R. (2010). Why some road safety problems are more difficult to solve than others?. Accident Analysis and Prevention, 42(4), 1089-1096.

Hauer, E. (1994). Can one estimate the value of life or is it better to be dead than stuck in traffic? Transportation Research Series A, 28(2), 109-118.

Harker, P.T. (1987). Incomplete pairwise comparisions in the analytival hierarchy process. Mathematical Modelling, 9(11), 837-848.

Hauer, E. (2011). Computing what the public wants: Some issues in road safety cost-benefit analysis. Accident Analysis and Prevention, 43(1), 151-164.

Henderson, R.D. \& Dutta, S.P. (1992). Use of the analytic hierarchy process in ergonomic analysis. International Journal of Industrial Ergonomics, 9(4), 275-82.

Joksch, H.C. (1975). A critical appraisal of the applicability of cost- benefit analysis to highway traffic safety. Accident Analysis and Prevention, 7(2), 133-153.

Ivehammar, P. (2008). Valuing in actual travel time environmental encroachment caused by transport infrastructure. Transportation Research Part D: Transport and Environment, 13(7), 455-461.

Wijnen, W., Wesemann, P. \& Blaeij, A. (2009). Valuation of road safety effects in cost-benefit analysis. Evaluation and Program Planning, 32(4), 326-331.

Womer, N. K., Bougnol , M. L. \& Dula, J. H. (2006). Benefit- cost analysis using data envelopment analysis. Annals of Operations Research, 145(1), 229-250.

Saaty, T.L., \& Vargas, L.G. (1984). Inconsistency and rank preservation. Mathematical Psychology, 28(2), 205-214.

Salling, K.B. \& Banister, D. (2009). Assessment of large transport infrastructure projects: The CBADK model. Transportation Research Part A, 43(9-10), 800-813.

Torfi, F., Zanjirani Farahani, R. \& Rezapour, S. (2010). Fuzzy AHP to determine the relative weights of evaluation criteria and Fuzzy TOPSIS to rank the alternatives. Applied Soft Computing, 10(2), 520-528.

Zahedi, F. (1987). A utility approach to the analytic hierarchy process. Mathematical Modelling, 9(35), 387-395. 